\title{
Parenting style and child-feeding behaviour in predicting children's weight status change in Taiwan
}

\author{
Ho-Jui Tung ${ }^{1, *}$ and Ming-Chin Yeh ${ }^{2}$ \\ ${ }^{1}$ Department of Healthcare Administration, Asia University, 500 Lioufeng Road, Wufeng, Taichung 41354, \\ Taiwan: ${ }^{2}$ Nutrition Program, CUNY School of Public Health at Hunter College, City University of New York, \\ New York, NY, USA
}

Submitted 13 April 2012: Final revision received 17 November 2012: Accepted 25 November 2012: First published online 18 January 2013

\begin{abstract}
Objective: The prevalence of overweight and obesity among children is on the rise worldwide. Prior studies find that parents' child-feeding practices are associated with child weight status and the efficacy of specific parental child-feeding practices can be moderated by parenting styles. In the current longitudinal study, we examined the associations between child-feeding practices and weight status changes over 1 year among a sample of school-aged children in Taiwan.

Design: In autumn 2008, a child-feeding questionnaire and parenting-style questionnaire were administered to parents of the second and fourth graders in an elementary school in Taiwan. The weight and height of the students were measured by a trained school nurse in 2008 and again in 2009.

Setting: An elementary school in central Taiwan.

Subjects: A total of 465 parent-child pairs were included in the analysis.

Results: Using a gender- and age-adjusted BMI classification scheme issued by the Taiwan Department of Health, $29 \cdot 2 \%$ of the students were considered overweight at the 2009 measurement. Controlling for 2008 weight status revealed moderating effects of parenting style on the relationship between child-feeding practices and child weight status. Both authoritative and authoritarian mothers might monitor their children's dietary intake; however, the effectiveness of this practice was better, in terms of weight status control, among the authoritative mothers.

Conclusions: Findings suggest that parenting styles have a moderating effect on specific parental child-feeding practices. Parenting styles and parent's feeding practices could be an important focus for future public health interventions addressing the rising childhood obesity epidemic.
\end{abstract}

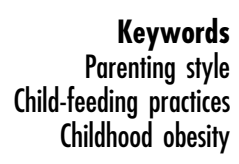

The prevalence of overweight and obesity among children is on the rise worldwide. In 2010, the WHO estimated the number of overweight children under the age of 5 years to be over 42 million, with close to 35 million overweight children living in developing countries ${ }^{(1)}$. Overweight and obese children are likely to stay obese into adulthood and are likely to develop diseases such as diabetes, CVD and cancer ${ }^{(2)}$. The increasing burden of obesity is alarming because of its broad spectrum of acute and long-term complications imposing substantial human and economic costs on individuals, families, health-care systems and society ${ }^{(3)}$. One study indicates that rising childhood obesity rates will cut average life expectancy in the USA at birth by 2-5 years in the coming decades, such that the current generation could be the first one since World War II to have a shorter life expectancy than its parents ${ }^{(4)}$. Thus, examining factors that contribute to effective prevention strategies and programmes to address this significant public health problem is urgently needed.

\section{Childbood obesity in Taiwan}

Similar to this rising tide of childhood obesity seen elsewhere, overweight and obesity among the children in Taiwan have increased considerably since the 1990s. In 1994, a survey of adolescents aged 12-15 years in Taipei found that about $16 \cdot 6 \%$ of boys and $11 \cdot 1 \%$ of girls were obese, while an additional $11 \cdot 6 \%$ of boys and $10 \cdot 2 \%$ of girls were overweight ${ }^{(5)}$. By 2002 , according to the Nutrition and Health Survey in Taiwan ${ }^{(6)}$, the overall prevalence of overweight and obesity among children aged $6-13$ years was $15 \cdot 5 \%$ and $14.7 \%$ in boys and $14 \cdot 4 \%$ and $9 \cdot 1 \%$ in girls ${ }^{(7)}$. Another survey conducted by 
the Taiwan Ministry of Education in 2005-2006 found that about $15 \%$ of the elementary-school students were overweight and 10\% were considered obese. These numbers clearly indicate that overweight and obesity among children and adolescents is an urgent public health problem in Taiwan. This rising prevalence of childhood obesity has been attributed to changes in diet, physical activity and nutritional status among Taiwanese children $^{(8)}$.

\section{Parental control and childbood obesity}

Parents, as food providers, enforcers and role models, certainly have a strong influence in shaping their children's dietary behaviour and weight status ${ }^{(9)}$. However, studies have documented that parental control in children's eating may have unintended consequences with regard to children's weight. Birch and Davison indicated that parental feeding restriction is often prompted by perceptions and concerns pertaining to the child's risk for obesity ${ }^{(10)}$. There is evidence that parental control in child feeding could have adverse effects on children's eating behaviours and weight status $^{(10,11)}$. That is, for children perceived as overweight, their parents may attempt to manage their weight status by restricting their dietary intake which, in turn, may make things worse. Musher-Eizenman and Holub studied a sample of ninety-eight parents and reported that, when parents restricted what their children ate for weight reasons, their child ate more when given free access to snack foods ${ }^{(12)}$. As suggested by Rhee ${ }^{(13)}$, 'it appears that restrictive feeding behaviors can have a differentiated effect on a child's weight depending on the child's overweight risk or current weight status, resulting in more harm among those who are genetically or biologically at risk and those who are already overweight'.

In a prospective analysis of parental feeding attitudes and child BMI, Faith et al. found that parental attitudes were stable over a 2-year period ${ }^{(14)}$. After controlling for prior child weight status, they also concluded that some parental control of child feeding would increase a standardized BMI score among high-risk children, suggesting a reciprocal influence between child and parent ${ }^{(14)}$. These findings underscore the need to assess the role of parents' child-feeding practices within the family context to better understand the aetiology of childhood obesity.

\section{Parenting style and childbood obesity}

As mentioned above, it seems that the impact of specific parent-child feeding practices on child weight status should be understood within a context of family functioning and parenting style. According to Baumind, an early pioneer in the research on parenting style, there are three styles of parenting: authoritative, authoritarian and permissive ${ }^{(15)}$. Authoritative parenting style refers to a parent who demands that the child 'comply with a reasonable set of rules and is simultaneously responsive to the child's needs and supportive of the child's autonomy and individuality'.
An authoritarian parenting style refers to a parent who stresses the importance of compliance, conformity, parental control, respect for authority and maintaining $\operatorname{order}^{(16)}$. Maccoby and Martin ${ }^{(17)}$ later proposed another typology of parenting style along two dimensions: 'demandingness' and 'responsiveness' of parents. Here, 'demandingness' refers to expectations for displays of maturity by their children, parental control and discipline, whereas 'responsiveness' means parental displays of warmth, sensitivity, affection and involvement with their children. Four types of parenting styles can be derived from this conceptualization: authoritative, authoritarian, permissive and neglectful. An authoritative parent is one who scores high on both 'demandingness' and 'responsiveness'. By the same token, an authoritarian parent would score high on 'demandingness' but low on 'responsiveness' and a permissive parent would be just the opposite of an authoritarian parent in the two dimensions.

Evidence has shown that authoritative parenting is associated with numerous positive outcomes in children's development, such as higher academic achievement, increase of self-regulatory ability, more frequent use of adaptive strategies and fewer risk-taking behaviours ${ }^{(18,19)}$. Nutrition research has begun to study this construct in an effort to understand the influence of parenting styles on children's eating behaviours and nutrition-related outcomes. For example, a study by Kremers et $a l^{(20)}$ found that fruit consumption and fruit-specific cognitions were most favourable among adolescents who were being raised under an authoritative parenting style. Results from studies examining the effects of parenting style on fruit and vegetable consumption or child weight-related behaviours generally support that a parenting style high in demandingness and responsiveness is associated with more healthy outcomes ${ }^{(21,22)}$. A study conducted in the Netherlands found that how parenting style was perceived by adolescents had a moderating effect on the effectiveness of food-related parenting practices in terms of the consumption of sugar-sweetened beverages ${ }^{(23)}$. Studies done by Musher-Eizenman and Holub ${ }^{(12)}$ and by Joyce and Zimmer-Gembeck ${ }^{(24)}$ also documented moderating effects of parenting style on the relationship between restrictive feeding practices and children's eating habits and weight outcomes. Another study found that an authoritative parenting style predicted better glycaemic control and adherence to the treatment regimen among children with type 1 diabetes $^{(25)}$. Finally, in a review of key studies on parenting style and weight-related symptoms and behaviours among adolescents, Enten and Golan ${ }^{(26)}$ concluded that positive food-related behaviours of adolescents are supported by parents' use of an authoritative parenting style. However, a great majority of these studies were cross-sectional in design.

A few studies adopted a longitudinal approach to examine the relationship between parenting style and child's weight status. Rhee et al. ${ }^{(27)}$ examined the direct 
effects of parenting style on weight status among a group of first graders and Berge et $a l .{ }^{(28)}$ found that authoritative parenting style may play a protective role against overweight in adolescents. Both studies demonstrated that children with authoritarian parents were more likely to be overweight, when compared with children of authoritative parents. These studies highlight that an understanding of how parenting styles are associated with overweight risk could lead to the development of comprehensive interventions for obesity prevention among young children. A review by Ventura and Birch ${ }^{(29)}$ summarized both causal and correlational evidence regarding the reciprocal influences between parenting and child's eating and weight and indicated plausible pathways for these influences to take place. Another review by Sleddens et $a l^{(30)}$ specifically pointed out the moderating role of parenting style on the relationship between parenting practices and children's anthropometric outcomes.

Actually, in the socialization literature, Darling and Steinberg ${ }^{(31)}$ have long proposed that parenting style should be conceptualized as a context that moderates the influence of specific parenting practices on the child. They argue that parenting style influences child development through three characteristics of parents: (i) the values and goals parents have in socializing their children; (ii) the parenting practices they employ; and (iii) the attitudes they express towards their children. They further distinguish the concept of parenting practices from parenting style and contend that parenting practices are 'behaviors defined by specific content and socialization goals' and parenting style refers to parent-child interactions across various situations ${ }^{(31)}$. Based on this contextual model of parenting style, if the outcome of interest is child's weight status, parenting style would influence this outcome primarily through its moderating effects on the relationship between parental child-feeding practices and child's weight status. Rhee ${ }^{(13)}$ also suggests that parenting styles may moderate the relationship between child-feeding behaviours and weight outcomes so that a behavior delivered within the context of a more positive parenting style will have a different impact on the child than one delivered in a more negative parenting style'.

In the present study, we used a sample of school-aged children (second and fourth graders) in central Taiwan to empirically examine the moderating effects of parenting style on the associations between child-feeding behaviours and weight status changes over a 1-year period.

\section{Methods}

\section{Design}

The current longitudinal study involved a survey of parents' feeding behaviour and parenting style in 2008 and measurement of children's weights and heights at the beginning of the 2008 autumn semester (baseline) and again in the 2009 autumn semester.

\section{Sample and data collection}

After approval of the study project by the Institutional Review Board at Asia University, Taiwan, parents of all second and fourth graders in a nearby elementary school in central Taiwan were contacted via an invitation letter brought home by their children in the autumn semester of 2008. If the parents agreed to participate in the study, they were asked to sign a consent form and to complete a Parenting Styles and Dimension Questionnaire (PSDQ) and a Child Feeding Questionnaire (CBQ), along with providing their demographic information.

Traditionally, in Taiwan, it is the mother who is responsible for preparing meals and foods for their children. Children were instructed by their teachers to hand the questionnaires to their mother. For children whose mothers did not live with them, their fathers were asked to rate themselves and the parenting styles of their spouse. The completed questionnaires were brought back by the children to their class teachers, who then handed the questionnaires to the researcher. Parents also gave permission to the researcher to access their children's weight and height information as measured by a trained school nurse at the student health centre. By the autumn of 2009 , after all of the returning students had completed their weight and height measurements at the same student health centre by a trained school nurse, the 2008 data were matched with the newly measured 2009 weight and height data. Six returned questionnaires containing only the father's responses to the survey scales in 2008 were excluded and another thirty students had transferred to other schools or had moved out of the school district as of the 2009 data collection period. As a result, the current analyses were performed on 465 (231 boys and 234 girls) students with longitudinal weight and height data. This represents over $90 \%$ of the total second- and fourth-grade students in that elementary school in 2008.

\section{Measures}

Both questionnaires were translated into Chinese and pilot-tested on a small group of sixteen teachers with child-rearing experiences from the same elementary school. Suggestions from these teachers on the wording of the translated items were incorporated into the final version of the questionnaires.

\section{Parenting style}

The PSDQ ${ }^{(32)}$, containing sixty-two statements regarding different responses to child behaviour, was used to measure parenting styles. The PSDQ was designed to tap into Baumrind's three dimensions of parenting (authoritative, authoritarian and permissive $)^{(33)}$. Items use a 5-point Likert scale ranging from never $(=1)$ to always $(=5)$. 
Of the sixty-two items of the PSDQ, twenty-seven were authoritative parenting-related questions (this subscale has an internal consistency of Cronbach's $\alpha=0.93$ ) and these twenty-seven were summed to obtain an overall authoritative parenting score. Similarly, a twenty-item authoritarian parenting subscale (Cronbach's $\alpha=0 \cdot 81$ ) and a fifteen-item permissive parenting subscale (Cronbach's $\alpha=0.65)$ were also summed to obtain an overall score for each. After reversing the scoring of three items with negative statements, a larger score indicates an increased use of parenting practices associated with a particular parenting style. For each of the three types of parenting, the median score was used as the cut-off point to classify a mother as more inclined or less inclined to a particular parenting style.

\section{Child-feeding practices}

Parent's child-feeding practices were measured by using the CFQ developed by Birch and co-workers ${ }^{34,35)}$. This questionnaire has seven subscales assessing parents' attitudes and practices towards feeding their children, namely: (i) perceived responsibility, (ii) perceived parent weight, (iii) perceived child weight, (iv) concern about child weight, (v) restriction to eat, (vi) pressure to eat and (vii) monitoring. In the perceived child weight subscale there are six items asking how parents would classify their children's weight at different time periods (from the first year of life to eighth grade). Since the children in our sample were under 10 years old, two items asking about perceived child weight beyond age 10 were deleted from this subscale. As a result, twenty-nine items of the CFQ were adopted for the present study and all seven of these subscales of the CFQ had satisfactory internal consistency with Cronbach's $\alpha$ ranging from 0.65 to 0.91 .

\section{Child weight and height data}

Children's weight and height were measured at the school's student health centre by a trained school nurse. The weight and height measurements of every student are routinely collected and maintained by student health centres at the beginning of the autumn semester for all elementary-school children in Taiwan. Calibrated digital scales were used to measure weights and heights. Children were dressed in light clothing and weighed without their shoes. We obtained both the 2008 and 2009 measures of weights and heights to compute BMI (weight in kilograms divided by the square of height in metres) for the same child over 1 year.

A gender- and age-adjusted BMI classification scheme issued in 2007 by Taiwan's Department of Health was used to determine the BMI status of sampled children. A child was considered 'overweight' if his/her BMI was $\geq 85$ th percentile and $<95$ th percentile for a specific age and gender; while a child with $\mathrm{BMI} \geq 95$ th percentile for a specific age and gender was considered 'obese'.

\section{Statistical analysis}

Descriptive statistics of both 2008 and 2009 BMI status were compared using ANOVA and associations between each of the seven subscales of child-feeding practices and child BMI status were examined using correlation coefficients. Additionally, in order to test the moderating effects of parenting styles on the relationship between CFQ subscales and weight status changes over the 1-year period, the 465 mothers were divided into two groups (more inclined or less inclined to a particular parenting style) based on their score on each of the three dimensions of parenting style, namely authoritative, authoritarian and permissive. Using the median scores as the cut-off points, three separate logistic regression models were conducted to predict children's overweight status (BMI $\geq 85$ th percentile) in 2009, while controlling for children's BMI status in 2008. All analyses were conducted with the SAS statistical software package version $9 \cdot 0$ and the statistical significance level was set as $P<0 \cdot 05$.

\section{Results}

\section{Descriptive data}

Among the 465 mother-child pairs included in the present study, $76 \cdot 8 \%$ of the mothers were between 30 and 40 years old, with a mean age of 37 years. Over $90 \%$ of them had graduated from high school. The mean age of the children was 8.45 years for boys and 8.35 years for girls in 2009 (see Table 1). Using the gender- and ageadjusted BMI classification scheme issued by Taiwan's Department of Health, $16 \cdot 5 \%$ of the boys (thirty-eight out of 231 ) and $12 \cdot 4 \%$ of the girls (twenty-nine out of 234) were considered obese (BMI $\geq 95$ th percentile) and another $18.6 \%$ of the boys (forty-three out of 231) and $11.1 \%$ of the girls (twenty-six out of 234) were considered overweight (BMI $\geq 85$ th and $<95$ th percentile) in 2009 .

Changes in the sampled children's weight status over the 1-year period were evaluated using the aforementioned BMI classification scheme. There were 363 (78\%) children whose BMI status did not change over the year. However, fourteen children who were overweight in 2008 became obese by 2009. Another sixteen children who were of normal weight in 2008 became overweight or obese by 2009 . We calculated a $\boldsymbol{\kappa}$ coefficient to evaluate the extent of changes between the two measurements. The $\kappa$ value of 0.657 indicates a fair agreement between the two but with some variance. The descriptive statistics for scores on the seven subscales of the CFQ and the three parenting scores are also summarized in Table 1. None of these measures differed significantly between boys and girls.

We examined the correlation patterns among the seven child-feeding practices by gender (above the diagonal for girls and below the diagonal for boys in Table 2) and found 
Table 1 Sample characteristics and parental CFQ scores according to child gender: parent-child pairs $(n 465)$ from an elementary school in central Taiwan, 2008 and 2009

\begin{tabular}{|c|c|c|c|c|}
\hline & \multicolumn{2}{|c|}{ Boys (n 231) } & \multicolumn{2}{|c|}{ Girls ( $n$ 234) } \\
\hline & Mean or $n$ & SD or $\%$ & Mean or $n$ & SD or $\%$ \\
\hline Mother's age (years) & $37 \cdot 05$ & $4 \cdot 19$ & $37 \cdot 03$ & 4.95 \\
\hline \multicolumn{5}{|l|}{ Mother's education (\%) } \\
\hline Junior high or less & - & $9 \cdot 9$ & - & $12 \cdot 8$ \\
\hline Senior high & - & $53 \cdot 7$ & - & $55 \cdot 1$ \\
\hline Some college and above & - & $36 \cdot 4$ & - & $32 \cdot 1$ \\
\hline \multicolumn{5}{|l|}{ Father's education (\%) } \\
\hline Junior high or less & - & $11 \cdot 3$ & - & $17 \cdot 1$ \\
\hline Senior high & - & $55 \cdot 8$ & - & $48 \cdot 7$ \\
\hline Some college and above & - & $32 \cdot 9$ & - & $34 \cdot 1$ \\
\hline Child's mean age (years) in 2009 & $8 \cdot 45$ & $1 \cdot 03$ & $8 \cdot 35$ & $1 \cdot 02$ \\
\hline \multicolumn{5}{|l|}{ Scores on CFQ subscales } \\
\hline Perceived responsibility & $12 \cdot 5$ & $2 \cdot 6$ & $12 \cdot 6$ & $2 \cdot 2$ \\
\hline Perceived child weight & $12 \cdot 0$ & $1 \cdot 8$ & $11 \cdot 7$ & 1.9 \\
\hline Concern about child weight & $7 \cdot 4$ & $3 \cdot 1$ & $7 \cdot 7$ & $3 \cdot 1$ \\
\hline Restriction to eat & $30 \cdot 4$ & $5 \cdot 0$ & $30 \cdot 0$ & $5 \cdot 4$ \\
\hline Pressure to eat & $16 \cdot 1$ & $3 \cdot 0$ & $16 \cdot 1$ & $2 \cdot 9$ \\
\hline Monitoring & $11 \cdot 3$ & $2 \cdot 6$ & $10 \cdot 9$ & $2 \cdot 7$ \\
\hline Perceive parent weight & $12 \cdot 1$ & $1 \cdot 4$ & $11 \cdot 9$ & $1 \cdot 6$ \\
\hline \multicolumn{5}{|l|}{ Scores on parenting styles } \\
\hline Authoritative parenting & $106 \cdot 3$ & $15 \cdot 1$ & $104 \cdot 7$ & $16 \cdot 9$ \\
\hline Authoritarian parenting & $43 \cdot 1$ & $8 \cdot 6$ & $44 \cdot 1$ & $8 \cdot 9$ \\
\hline Permissive parenting & $30 \cdot 1$ & $5 \cdot 3$ & $30 \cdot 5$ & $6 \cdot 4$ \\
\hline \multicolumn{5}{|l|}{ BMI status in $2008(n, \%)$} \\
\hline Obese & 33 & $14 \cdot 3$ & 31 & $13 \cdot 2$ \\
\hline Overweight & 48 & $20 \cdot 8$ & 28 & $12 \cdot \overline{0}$ \\
\hline Normal weight & 123 & $53 \cdot 2$ & 133 & $56 \cdot 8$ \\
\hline Underweight & 27 & $11 \cdot \overline{7}$ & 42 & $17 \cdot 9$ \\
\hline \multicolumn{5}{|l|}{ BMI status in $2009(n, \%)$} \\
\hline Obese & 38 & $16 \cdot 5$ & 29 & $12 \cdot 4$ \\
\hline Overweight & 43 & $18 \cdot 6$ & 26 & $11 \cdot 1$ \\
\hline Normal weight & 119 & $51 \cdot 5$ & 125 & $53 \cdot 4$ \\
\hline Underweight & 31 & $13 \cdot 4$ & 54 & $23 \cdot 1$ \\
\hline
\end{tabular}

CFQ, Child Feeding Questionnaire.

Data are presented as mean and standard deviation unless indicated otherwise.

Table 2 Correlation patterns among the seven parental child-feeding practices according to child gender: parent-child pairs ( $n$ 465) from an elementary school in central Taiwan, 2008 and 2009

\begin{tabular}{|c|c|c|c|c|c|c|c|}
\hline & \multicolumn{7}{|c|}{ Girls } \\
\hline & Responsibility & $\begin{array}{l}\text { Perceived } \\
\text { child weight }\end{array}$ & $\begin{array}{l}\text { Concern about } \\
\text { child weight }\end{array}$ & $\begin{array}{l}\text { Restriction } \\
\text { to eat }\end{array}$ & $\begin{array}{l}\text { Pressure } \\
\text { to eat }\end{array}$ & Monitor & $\begin{array}{c}\text { Perceived } \\
\text { parent weigh }\end{array}$ \\
\hline \multicolumn{8}{|l|}{ Boys } \\
\hline Responsibility & - & -0.04 & -0.02 & $0 \cdot 12$ & $0 \cdot 22^{\star \star}$ & $0 \cdot 32^{\star \star}$ & -0.07 \\
\hline Perceived child weight & $-0 \cdot 11$ & - & $0 \cdot 37^{\star \star}$ & 0.07 & $-0 \cdot 29^{\star \star}$ & -0.05 & $0 \cdot 23^{\star \star}$ \\
\hline $\begin{array}{l}\text { Concern about child } \\
\text { weight }\end{array}$ & $-0 \cdot 10$ & $0.40^{* *}$ & - & $0 \cdot 14^{*}$ & $-0 \cdot 21^{\star *}$ & -0.03 & $0 \cdot 12$ \\
\hline Restriction to eat & 0.04 & 0.01 & $0 \cdot 13$ & - & $0 \cdot 24^{\star \star}$ & $0 \cdot 23^{\star \star}$ & 0.01 \\
\hline Pressure to eat & $0 \cdot 15^{\star}$ & $-0 \cdot 26^{\star \star}$ & $0 \cdot 12$ & $0 \cdot 37$ & - & $0 \cdot 19^{\star \star}$ & $-0 \cdot 13$ \\
\hline Monitor & $0 \cdot 33^{\star *}$ & 0.06 & 0.02 & $0 \cdot 14^{*}$ & 0.05 & - & -0.05 \\
\hline Perceived parent weight & -0.08 & $0 \cdot 22^{\star *}$ & $0 \cdot 25^{\star \star}$ & 0.08 & -0.08 & $-0 \cdot 10$ & - \\
\hline
\end{tabular}

${ }^{*}$ Correlation coefficients are significant at the 0.05 level (two-tailed).

${ }^{*}$ Correlation coefficients are significant at the 0.01 level (two-tailed).

that significant associations among different feeding practices were consistent with predicted directions. For example, perceived child weight had a positive association with concern about child weight $(r=0 \cdot 40$ among boys and $r=0.37$ among girls, both $P<0.01)$ and a negative association with pressure to eat $(r=-0 \cdot 26$ among boys and $r=-0 \cdot 29$ among girls, both $P<0 \cdot 01)$. Mothers who had a stronger perceived responsibility for child feeding also scored higher on pressure to eat and monitoring. These patterns of associations among the CFQ subscales indicated good validity of this instrument in measuring parental attitudes and practices about child feeding.

On the other hand, some contrasts between boys and girls were also observed from Table 2. Among the girls, if 
Table 3 Comparison of parental CFQ subscale mean scores according to child weight status and year: parent-child pairs $(n 465)$ from an elementary school in central Taiwan, 2008 and 2009

\begin{tabular}{|c|c|c|c|c|c|c|c|c|c|c|}
\hline \multirow[b]{3}{*}{ CFQ subscale } & \multicolumn{8}{|c|}{ Child BMI status in 2008} & \multirow[b]{3}{*}{$F(3,461)$} & \multirow[b]{3}{*}{$P$ value } \\
\hline & \multicolumn{2}{|c|}{ Underweight } & \multicolumn{2}{|c|}{ Normal weight } & \multicolumn{2}{|c|}{ Overweight } & \multicolumn{2}{|c|}{ Obese } & & \\
\hline & Mean & SD & Mean & SD & Mean & SD & Mean & SD & & \\
\hline Responsibility & $12 \cdot 2$ & $2 \cdot 5$ & $12 \cdot 4$ & $2 \cdot 5$ & $12 \cdot 5$ & $2 \cdot 4$ & $13 \cdot 2$ & $2 \cdot 2$ & $2 \cdot 24$ & 0.083 \\
\hline Perceived child weight & $10 \cdot 0$ & $2 \cdot 1$ & $11 \cdot 6$ & $1 \cdot 3$ & $12 \cdot 5$ & $1 \cdot 5$ & $14 \cdot 0$ & $1 \cdot \overline{7}$ & $80 \cdot 21$ & $<0.001$ \\
\hline Concern about child weight & $5 \cdot 8$ & $2 \cdot 6$ & $6 \cdot 9$ & $2 \cdot 9$ & $9 \cdot 3$ & $2 \cdot 8$ & $9 \cdot 9$ & $2 \cdot 4$ & $39 \cdot 92$ & $<0.001$ \\
\hline Restriction to eat & $30 \cdot 2$ & $5 \cdot 1$ & $30 \cdot 1$ & $5 \cdot 3$ & $30 \cdot 7$ & $4 \cdot 9$ & $30 \cdot 1$ & $4 \cdot 7$ & 0.243 & 0.866 \\
\hline Pressure to eat & $17 \cdot 2$ & $2 \cdot 4$ & $16 \cdot 4$ & $2 \cdot 8$ & $15 \cdot 6$ & $3 \cdot 1$ & $14 \cdot 2$ & $2 \cdot 8$ & $15 \cdot 43$ & $<0.001$ \\
\hline Monitoring & $11 \cdot 6$ & $2 \cdot 7$ & $11 \cdot 0$ & $2 \cdot 7$ & $10 \cdot 9$ & $2 \cdot 7$ & $10 \cdot 9$ & $2 \cdot 4$ & 0.97 & 0.409 \\
\hline \multirow[t]{4}{*}{ Perceived parent weight } & $11 \cdot 6$ & $1 \cdot 6$ & $11 \cdot 9$ & $1 \cdot 5$ & $12 \cdot 6$ & $1 \cdot 4$ & $12 \cdot 4$ & $1 \cdot 5$ & $8 \cdot 43$ & $<0.001$ \\
\hline & \multicolumn{8}{|c|}{ Child BMI status in 2009} & & \\
\hline & \multicolumn{2}{|c|}{ Underweight } & \multicolumn{2}{|c|}{ Normal weight } & \multicolumn{2}{|c|}{ Overweight } & \multicolumn{2}{|c|}{ Obese } & & \\
\hline & Mean & SD & Mean & SD & Mean & SD & Mean & SD & & \\
\hline Responsibility & $12 \cdot 9$ & $2 \cdot 4$ & $12 \cdot 6$ & $2 \cdot 4$ & $12 \cdot 5$ & $2 \cdot 4$ & $12 \cdot 0$ & $2 \cdot 6$ & 1.59 & $0 \cdot 191$ \\
\hline Perceived child weight & $10 \cdot 2$ & $2 \cdot 0$ & $11 \cdot 6$ & $1 \cdot 3$ & $12 \cdot 6$ & $1 \cdot 5$ & $14 \cdot 0$ & $1 \cdot 8$ & $81 \cdot 21$ & $<0.001$ \\
\hline Concern about child weight & $5 \cdot 9$ & $2 \cdot 6$ & $6 \cdot 9$ & $2 \cdot 8$ & $9 \cdot 6$ & $2 \cdot 9$ & $9 \cdot 8$ & $2 \cdot 4$ & $41 \cdot 17$ & $<0.001$ \\
\hline Restriction to eat & $29 \cdot 8$ & $5 \cdot 4$ & $30 \cdot 3$ & $5 \cdot 1$ & $30 \cdot 5$ & $5 \cdot 0$ & $30 \cdot 0$ & 4.9 & 0.36 & 0.782 \\
\hline Pressure to eat & $16 \cdot 9$ & $2 \cdot 8$ & $16 \cdot 5$ & $2 \cdot 7$ & $15 \cdot 6$ & $2 \cdot 9$ & $14 \cdot 4$ & $3 \cdot 2$ & $12 \cdot 67$ & $<0.001$ \\
\hline Monitoring & $11 \cdot 0$ & $2 \cdot 8$ & $11 \cdot 2$ & $2 \cdot 8$ & $10 \cdot 9$ & $2 \cdot 4$ & $11 \cdot 0$ & $2 \cdot 4$ & 0.32 & 0.801 \\
\hline Perceived parent weight & $11 \cdot 5$ & $1 \cdot 5$ & $11 \cdot 9$ & 1.5 & $12 \cdot 5$ & 1.5 & $12 \cdot 5$ & $1 \cdot 4$ & 8.07 & $<0.001$ \\
\hline
\end{tabular}

CFQ, Child Feeding Questionnaire.

Data are presented as mean and standard deviation.

a mother was concerned about her daughter's weight status, her feeding practices would involve more restriction to eat and less pressure to eat (a negative association). However, for the boys, none of these practices were significant strategies used by their mothers. This probably reflects a cultural expectation among Taiwanese parents that having an overweight girl is much worse than having an overweight boy.

\section{Child Feeding Questionnaire subscales and weight status}

Associations between parents' child-feeding practices and children's BMI status are presented in Table 3. In 2009, we found that mothers' mean scores for perceived child weight, concern about child weight, pressure to eat and perceived parent weight were significantly different across children's weight status. For example, parents' perceived child weight and concern about child weight increased from underweight to obese, while parents with underweight children used more pressure to eat than those with overweight children. These association patterns were all in the expected direction, which further provided confidence to our application of the instrument in a different culture and language setting.

\section{Moderating effects of parenting styles}

Findings of the moderating effects of parenting styles on the relationship between CFQ subscales and weight status change over a 1-year period are presented in Table 4 . The results showed that parenting styles moderated the association patterns between overweight status in 2009 and several child-feeding practices, such as concern about child weight and monitoring. After controlling for the prior year's weight status, the two feeding practices concern about child weight and monitoring were significant predictors of child overweight status, but only among children with a more authoritative mother. For a more authoritative mother, if she expressed more concern about her child's weight, the child would be more likely to be in an overweight status in 2009. At the same time, children with a more authoritative mother were less likely to be in an overweight status if their mothers used more monitoring (keeping track of the sweets, snacks and high-fat foods that their children eat) of their children's dietary intake.

The moderating effect of authoritarian parenting was contrastingly different from that of authoritative parenting. It can be seen from Table 4 that among the more authoritarian mothers, concern about child weight was not a significant predictor of children's overweight status in 2009, but the opposite was true among the less authoritarian mothers. More importantly, among mothers with a more authoritarian parenting style, monitoring was associated with an increased chance of having an overweight child in 2009, which is exactly opposite to the effect that monitoring practice has among the more authoritative mothers.

Finally, differences in association patterns between the more and less permissive mothers were also observed but were less striking. For the less permissive mothers, perceived child weight, in addition to their 2008 BMI status, was the only significant predictor of children's 2009 overweight status. For more permissive mothers, 
concern about child weight was the only significant predictor of their children's weight status in 2009, after controlling for 2008 weight status.

\section{Discussion}

Using a sample of 465 mothers and their second- and fourth-grade children in central Taiwan, the present study tested the moderating effect of parenting style on the associations between mothers' child-feeding behaviours and children's weight status changes over a 1-year period. Our findings demonstrate that parenting style has a moderating effect on the relationship between specific child-feeding practices and child's weight status. An authoritative mother may not differ from a non-authoritative mother in her intention to use certain feeding practices, but the outcomes of their feeding behaviours can be quite different. For example, both authoritative and authoritarian mothers may keep track of the sweets, snacks and high-fat foods that their children eat; however, the effectiveness of this parental practice was better, in terms of weight status 1 year later, among the authoritative mothers.

These findings are consistent with what Darling and Steinberg ${ }^{(31)}$ theorized, namely that parenting styles differ from parenting practices in that parenting styles set the tone for interactions, rather than being goal-directed attempts at socializing a child. In our case, parenting styles influenced a child development outcome indirectly through moderating the relationship between childfeeding practices and the weight status of a child. As Baumrind $^{(33)}$ argued, parenting styles change the nature of the interactions between parents and their children through the way interactions are presented. Our findings offer several important points for public health programmes aimed at preventing childhood obesity.

First, the family is the basic social institution in all societies and parents are usually the most important agent of socialization for children. Parental involvement is crucial in order to achieve success in any childhood obesity prevention programme. Birch and Ventura also suggest that future childhood obesity interventions should be designed to include a focus on parenting and parent-child interactions ${ }^{(36)}$. As depicted by Wardle and Carnell $^{(37)}$, authoritative mothers might create restrictions by not keeping certain foods in the house, where authoritarian mothers might create the same restriction by saying 'no'. Parents should know that children would experience these two restrictions quite differently.

Second, the current rising prevalence of overweight among children is related to the obesogenic environment in modern societies ${ }^{(38,39)}$. This environment encourages habitual energy intakes that are greater than habitual energy expenditures. Parents raising children in this kind of environment should be aware that some traditional feeding practices may lead to accelerated weight gain. Birch and Ventura $^{(36)}$ have listed some approaches parents should 
adopt in shaping their children's dietary behaviours, such as acting as positive role models of eating and sharing feeding responsibilities with children. Birch and Ventura also describe guidance on responsive feeding and discourage the use of coercive feeding practices ${ }^{(40)}$.

The present study has its limitations. We were only able to collect and analyse the BMI data for 1 year. Although we did observe patterns of change within this short time frame, a study with multiple-year observation will provide valuable insights as to whether these changes remain evident over a longer period of time. Also, our study participants were from Taiwan. Due to culture differences and potential difference in parenting styles, the findings may not be generalizable to other countries or cultures ${ }^{(41,42)}$. However, to have a healthy child is a universal goal for parents across all cultures. Parenting styles and parent's feeding practices could be an important focus for future public health interventions to reduce childhood obesity.

\section{Acknowledgements}

Sources of funding: This research received administrative supports from both the Asia University and Chiou-Te Elementary School in Tai-Chung, Taiwan. Conflicts of interest: None of the authors have any conflict of interests. Authorship responsibilities: H.-J.T. designed the study and supervised the data collection processes, conducted and interpreted the analysis, and composed the first draft of this manuscript. M.-C.Y. contributed to revising the draft and made valuable recommendations for points presented in the discussion. Acknowledgements: The authors thank Yao-Wen Chang for distributing and collecting the questionnaires for the study and for compiling the weight and height records from the school's student health centre.

\section{References}

1. World Health Organization (2000) Obesity: Preventing and Managing the Global Epidemic. WHO Technical Report Series no. 894. Geneva: WHO.

2. Reilly JJ \& Kelly J (2011) Long-term impact of overweight and obesity in childhood adolescence on morbidity and premature mortality in adulthood: systematic review. Int J Obes (Lond) 35, 891-898.

3. Wang YC, McPherson K, March T et al. (2011) Health and economic burden of the projected obesity trends in the USA and UK. Lancet 378, 815-825.

4. Olshansky SJ, Passaro DJ, Hershow RC et al. (2005) A potential decline in life expectancy in the United States in the 21st century. $N$ Engl J Med 352, 1138-1145.

5. Chu NF (2005) Prevalence of obesity in Taiwan. Obes Rev 6, 271-274

6. Tu SH, Hung YT, Chang HY et al. (2007) Nutrition and Health Survey of Taiwan Elementary School Children 2001-2002: research design, methods and scope. Asia Pac J Clin Nutr 16, Suppl. 2, 507-517.

7. Chu NF \& Pan WH (2007) Prevalence of obesity and its comorbidities among school children in Taiwan. Asia Pac J Clin Nutr 16, 601-607.
8. Hsieh PL \& FitzGerald M (2005) Childhood obesity in Taiwan: review of the Taiwanese literature. Nurs Health Sci 7, 134-142.

9. Stang J \& Loth KA (2011) Parenting style and child feeding practices: potential mitigating factors in the etiology of childhood obesity. J Am Diet Assoc 111, 1301-1305.

10. Birch LL \& Davison KK (2001) Family environmental factors influencing the developing behavioral controls of food intake and childhood overweight. Pediatr Clin North Am 48, 893-907.

11. Clarke HR, Goyder E, Bissell P et al. (2007) How do parents' child-feeding behaviours influence child weight? Implications for childhood obesity policy. J Public Health 29, 132-141.

12. Musher-Eizenman DR \& Holub SC (2006) Children's eating in the absence of hunger: the role of restrictive feeding practices. In Childhood Obesity and Health Research, pp. 135-156 [R Flamenbaum, editor]. Hauppauge, NY: Nova Science Publishers Inc.

13. Rhee K (2008) Childhood overweight and the relationship between parent behaviors, parenting style, and family functioning. Ann Am Acad Policy Soc Sci 615, 11-37.

14. Faith MS, Berkowitz RI, Stallings VA et al. (2004) Parental feeding attitudes and styles and child BMI: prospective analysis of a gene-environment interaction. Pediatrics 114, e429-e436.

15. Baumrind D (1978) Parental discipline patterns and social competence in children. Youth Soc 9, 239-276.

16. Zlotnik D \& Bornstein MH (2007) Effects of parenting styles. In Encyclopedia of Infant and Early Childhood Development, pp. 469-509 [MM Haith and J Benson, editors]. Oxford: Elsevier Ltd.

17. Maccoby EE, Martin JA (1983) Socialization in the context of the family: parent-child interaction. In Handbook of Child Psychology. vol. 4: Socialization, Personality, and Social Development, 4th ed., pp. 1-10 [PH Mussen and EM Hetherington, editors]. New York: Wiley.

18. Chassin L, Presson CC, Rose J et al. (2005) Parenting style and smoking-specific parenting practices as predictors of adolescent smoking onset. J Pediatr Psychol 30, 333-344.

19. Steinberg L, Elmen JD \& Mounts NS (1989) Authoritative parenting, psychological maturity, and academic success among adolescents. Child Dev 60, 1424-1436.

20. Kremers SP, Brug J, Vries HD et al. (2003) Parenting style and adolescent fruit consumption. Appetite 41, 43-50.

21. Blissett J (2011) Relationships between parenting style, feeding style, and feeding practices and fruit and vegetable consumption in early childhood. Appetite 57, 826-831.

22. Rodenburg G, Oenema A, Kremers SP et al. (2012) Parental and child fruit consumption in the context of general parenting, parental education and ethnic background. Appetite 58, 364-372.

23. van der Horst K, Kremers SP, Ferreira I et al. (2007) Perceived parenting style and practices and the consumption of sugar-sweetened beverages by adolescents. Health Educ Res 22, 295-304

24. Joyce JL \& Zimmer-Gembeck MJ (2009) Parent feeding restriction and child weight. The mediating role of child disinhibited eating and the moderating role of the parenting context. Appetite 52, 726-734.

25. Shorer M, David R, Schoenberg-Taz M et al. (2011) Role of parenting style in achieving metabolic control in adolescents with type 1 diabetes. Diabetes Care 34, 1735-1737.

26. Enten RS \& Golan M (2008) Parenting style and weightrelated symptoms and behaviors with recommendation for practice. Nutr Rev 66, 65-75.

27. Rhee K, Lumeng JC, Appugliese DP et al. (2006) Parenting style and overweight status in first grade. Pediatrics 117, 2047-2054. 
28. Berge JM, Wall M, Loth K et al. (2010) Parenting style as a predictor of adolescent weight and weight-related behaviors. J Adolesc Health 46, 331-338.

29. Ventura AK \& Birch LL (2008) Does parenting affect children's eating and weight status? Int J Behav Nutr Phys Act 5, 15 .

30. Sleddens EFC, Gerards SMPL, Thijs C et al. (2011) General parenting, childhood overweight and obesity-inducing behaviors: a review. Int J Pediatr Obes 6, e12-e27.

31. Darling N \& Steinberg L (1993) Parenting style as context: an integrated model. Psychol Bull 113, 487-496.

32. Robinson CC, Mandelco B, Olsen SO et al. (1995) Authoritative, authoritarian, and permissive parenting style: development of a new measure. Psychol Rep 77, 819-830.

33. Baumrind D (1989) Rearing competent children. In Child Development Today and Tomorrow, pp. 349-378 [W Damon, editor]. San Francisco, CA: Jossey-Bass.

34. Birch LL, Fisher JO, Grimm-Thomas K et al. (2001) Confirmatory factor analysis of the Child Feeding Questionnaire: a measure of parental attitudes, beliefs, and practices about child feeding and obesity proneness. Appetite 36, 201-210.

35. Anderson CB, Hughes SO, Fisher JO et al. (2005) Crosscultural equivalence of feeding beliefs and practices: the psychometric properties of the child feeding questionnaire among Blacks and Hispanics. Prev Med 41, 521-531.

36. Birch LL \& Ventura AK (2009) Preventing childhood obesity: what works? Int J Obes (Lond) 33, Suppl. 1, S74-S81.

37. Wardle J \& Carnell S (2007) Parental feeding practices and children's weight. Acta Paediatr Suppl 96, 454, 5-11.

38. Harris JL, Pomeranz JL, Lobstein T et al. (2009) A crisis in the marketplaces: how food marketing contributes to childhood obesity and what can be done. Annu Rev Public Health 20, 211-225.

39. Zeller MH, Reiter-Purtill J, Modi AC et al. (2007) Control study of critical parent and family factors in the obesogenic environment. Obesity (Silver Spring) 15, 126-136.

40. Brown R \& Ogden J (2004) Children's eating attitudes and behaviour: a study of the modeling and control theories of parental influence. Health Educ Res 19, 261-271.

41. Arredondo EM, Elder JP, Ayala GX et al. (2006) Is parenting style related to children's healthy eating and physical activity in Latino families? Health Educ Res 21, 862-871.

42. Olvera N \& Power TG (2010) Parenting styles and obesity in Mexican American children: a longitudinal study. J Pediatr Psychol 35, 243-249. 